\title{
AVALIAÇÃO MORFOLÓGICA DE CÓRNEAS DE COELHOS CRIOPRESERVADAS COM ETILENOGLICOL
}

\author{
Lorena Borges Alves ${ }^{1}$, Duvaldo Eurides ${ }^{2}$, Lilian Vieira de Andrade ${ }^{3}$, Luiz Antônio Franco da Franco \\ da Silva ${ }^{4}$, Benito Juarez Nunes Alves de OliveirA ${ }^{5}$, Luiz Augusto de SouzA ${ }^{5}$
}

1 - Professora da Universidade Presidente Antônio Carlos

2 -Prof. Dr. Faculdade de Medicina Veterinária - Universidade Federal de Uberlândia duvaldo.eurides@pesquisador.cnpq.br

3 - Médica Veterinária pela Universidade Federal de Uberlândia

4 - Prof. Dr. da Escola de Veterinária e Zootecnia da Universidade Federal de Goiás

5 - Alunos do Programa de Pós-graduação Saúde Animal/EV/UFG

\section{RESUMO}

Avaliou-se o etileno glicol com criopreservador de córnea de coelhos. Foram colhidas córneas do bulbo ocular direito e esquerdo de 10 cadáveres de coelhos adultos, machos, da raça Nova Zelândia, com massa corporal variando de $4,0 \mathrm{~kg}$ a $5,0 \mathrm{~kg}$. As peças foram obtidas imediatamente após o abate dos animais realizado em abatedouro. As córneas foram removidas com uma margem de $2,0 \mathrm{~mm}$ de esclera e banhadas em solução fisiológica $0,9 \%$. As córneas dos bulbos oculares direitos foram fixadas em formol, incluídas em parafina e coradas em hematoxilina-eosina para avaliação em microscopia de luz. As dos globos oculares esquerdos foram imersas em frascos criogênicos contendo solução salina tamponada em fosfato, $0,4 \%$ de albumina sérica bovina e 1,5 molar de etilenoglicol. Os frascos foram congelados em nitrogênio líquido à temperatura de $-196^{\circ} \mathrm{C}$ durante um período de 60 dias. Após descongelamento, as córneas foram submetidas à análise macroscópica e mensuradas a partir de imagens digitalizadas. A preservação de córneas de coelhos com etilenoglicol, em nitrogênio líquido, não ocasiona alterações na transparência, estruturais e morfométricas das camadas que compõem a córnea.

PALAVRAS-CHAVE: Coelho; córnea; criopreservação.

\section{MORPHOLOGICAL EVALUATION OF RABBIT CORNEA CRYOPRESERVED WITH ETHYLENE GLYCOL}

Rabbit corneas, cryopreserved with ethylene glycol, were evaluated. Corneas of the right and left ocular globes were collected from eleven New Zelanda male rabbits, weighing between $4.0 \mathrm{~kg}$ and $5.0 \mathrm{~kg}$, immediately after the animals were slaughtered. The corneas were removed with a $2.0 \mathrm{~mm}$ edge of sclera and washed in physiological solution $0.9 \%$. The right corneas were fixed in formaldeide, enclosed in paraffin, stained in hematoxyline eosine for evaluation in light microscopy. The left corneas were immersed in cryoprotect bottles containing phosphate-buffered saline solution, $0.4 \%$ of bovine albumen and 1.5 molar of ethylene glycol. The bottles were frozen for 60 days at $-196^{\circ} \mathrm{C}$ in liquid nitrogen. After thawing, they were submitted to 
macrocospic analysis, and measured from digital images. The rabbits' corneas preservated with ethylene glycol in

KEYWORDS: córnea; cryopreserved; rabbit.

\section{INTRODUÇÃO}

Lesões corneais nos animais podem provocar opacidade e deformações que podem comprometer a nitidez da imagem e, dependendo de sua gravidade, conduzir à cegueira (ANDRADE \& LAUS, 1998).

Úlceras corneais, descemetoceles e perfurações têm sido tratadas por diferentes métodos, como retalhos tarsoconjuntivais (WHITLEY, 1991; SLATTER, 2005), transposição lamelar corneoescleral (PARSHALL Jr, 1973), flap de membrana nictitante (WHITLEY, 1991; SLATTER, 2005), enxertos pediculados de conjuntiva (LAUS et al., 1996; MORALES et al., 1996), lentes de contato (WILLIANS, 1991), enxertos conjuntivais livres (KUHNS, 1979), ceratoplastias lamelares (BERNIS, 1980), enxertos autólogos, livres, de córnea e pediculados de conjuntiva (LAUS et al., 1996), cápsula esplênica de bovino na ceratoplastia lamelar em coelhos (EURIDES, 2006) e membrana amniótica (BARROS et al., 1998; PONTES et al., 2008).

Córneas de cães foram preservadas para transplantes em glicerina $98 \%$, solução supersaturada de açúcar a 300\% (GONÇALVES et al., 2003), de coelhos, em solução contendo dextrano $10 \%$ (WEEKERS \& MICHIELS, 1976; HALBERSTADT et al., 2003) e em polietileno e sulfato de condroitina (ROUTLEDGE \& ARMITAGE, 2003), de humanos, em solução de 1,2 propanodiol $10 \%$ e solução de dimetilssulfóxido 7\% (O'NEILL et al., 1967; CANALS et al., 1999) e de cães e gatos, em solução de Optisol GS (ARNDT et al., 2001).

Para obtenção de bons resultados nos transplantes de córneas preservadas, é necessária a utilização de métodos que mantenham sua integridade anatomofuncional (ALMEIDA, 1974). É imprescindível que o epitélio posterior esteja íntegro por possuir células de vida curta, que não se regeneram e são facilmente afetadas por traumas mecânicos ou por alterações de $\mathrm{pH}$ do meio (WHITLEY, 1991).

O etilenoglicol tem sido utilizado para a criopreservação, em nitrogênio líquido a $-196^{\circ} \mathrm{C}$, do sêmen de várias espécies de animais como cães (SOARES et al. 2002), ovinos (MORAES et al., 1998) e equinos (ALVARENGA et al., 2000), com liquid nitrogen caused no structural nor morphometry alterations at the layers that compose the cornea.

bons resultados.

Neste experimento, avaliou-se a integridade e as medidas das camadas que compõem a córnea do coelho, criopreservadas em nitrogênio líquido a $196^{\circ} \mathrm{C}$, com etilenoglicol, através da análise morfológica e morfométrica. Este projeto aprovado pela comissão de ética CEUA-UFU: 044/08, parecer 060/2008.

\section{MATERIAL E MÉTODOS}

Foram colhidas córneas do bulbo ocular direito e esquerdo de 10 cadáveres de coelhos adultos, machos, da raça Nova Zelândia e pesando de 4,0kg a 5,0kg. As peças foram obtidas imediatamente após o abate dos animais em abatedouro. Os doadores não apresentavam clinicamente doenças infectocontagiosas e as córneas foram avaliadas com oftalmoscopia direta para excluir as portadoras de alterações. As córneas foram removidas com tesoura incluindo $2,0 \mathrm{~mm}$ da esclera e lavadas em solução fisiológica $0,9 \%$ (Solução fisiológica a $0,9 \%$. JP Indústria Farmacêutica. Ribeirão Preto, SP.) (Figura 1).

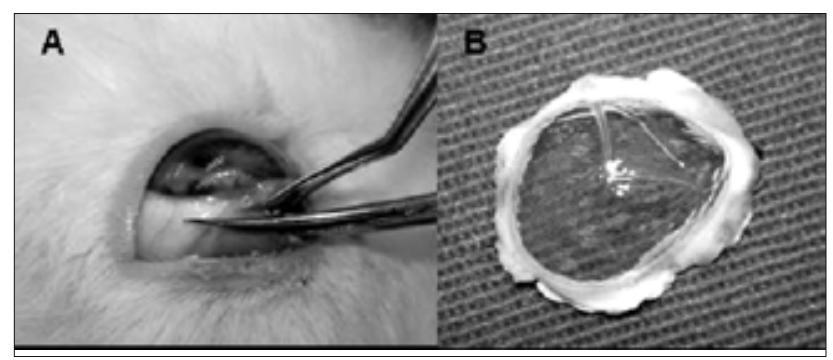

Figura 1. Córnea de coelho removida com tesoura com aproximadamente $2,0 \mathrm{~mm}$ da esclera (A e B).

Córneas do bulbo ocular direito (Grupo controle, $\mathrm{n}=10$ ) foram fixadas em formol a $10 \% \mathrm{du}$ rante três dias. As do bulbo ocular esquerdo (Grupo criopreservado, $\mathrm{n}=10$ ) foram imersas em tubos criogênicos ${ }^{1}$, contendo solução salina tamponada com fosfato (PBS), $0,4 \%$ de albumina sérica bovina e 1,5 molar de etilenoglicol ${ }^{2}$, e permaneceram em temperatura ambiente por 20 minutos. Os frascos

1 - Tubos criogênicos. Nutrientes celulares. Campinas, SP.

2 - Etilenoglicol. Nutricell. Nutrientes celulares. Campinas, SP. 
foram colocados no vapor de nitrogênio, $5,0 \mathrm{~cm}$ acima do nível de nitrogênio, por 20 minutos e, em seguida, mergulhados em nitrogênio líquido, durante 60 dias.

O descongelamento foi realizado em banhomaria a $38^{\circ} \mathrm{C}$ por, no mínimo, 30 segundos e, para remoção do crioprotetor, as córneas foram colocadas em solução de PBS, com $0,4 \%$ de albumina sérica bovina, onde permaneceram durante cinco minutos. Os segmentos corneanos do grupo controle e criopreservados foram analisados quanto à transparência e em seguida fixados em formol $10 \%$ durante três dias e inclusos em parafina. Com a utilização do micrótomo $^{3}$ foram obtidos cortes histológicos transversais de 5,0 $\mu \mathrm{m}$, corados em hematoxilina-eosina e montados com lamínula em bálsamo do Canadá. Através da microscopia de luz, com aumento de 10, 40 e $100 \mathrm{X}$, avaliou-se a integridade das camadas das córneas. As do grupo controle e criopreservado foram mensuradas através de imagens digitalizadas obtidas em microscópio Olimpus triocular BX40 acoplado à câmera Oly-200, conectada a um computador PC através de placa digitalizadora Data Translation 3153. As imagens foram analisadas utilizando-se o "software" HL Image $97++{ }^{4}$.

Foram utilizados o teste de Kolmogorov e o de Wilcoxon para verificar se as alterações foram estatisticamente significativas (TRIOLA, 2005).

\section{RESULTADOS E DISCUSSÃO}

O epitélio anterior é escamoso e não queratinizado, de espessura variável, com padrão básico de membrana basal, células epiteliais basais, aladas e superficiais escamosas (SLATTER, 2005). Neste experimento, o epitélio das córneas do grupo controle apresentou variação de espessura de 13 a $33 \mu \mathrm{m}$ e no criopreservado foi de 20 a $34 \mu \mathrm{m}$, valores não significativos.

$\mathrm{Na}$ criopreservação em nitrogênio líquido a $-196^{\circ}$ de 28 córneas humanas em solução de dextrano $10 \%$, ocorreu perda do epitélio posterior e, em duas córneas, essa camada encontrava-se totalmente necrosada (WEEKERS \& MICHIELS, 1976; HALBERSTADT et al., 2003). Neste experimento, a criopreservação foi realizada com etilenoglicol e as córneas apresentavam-se com epitélio posterior sol-

3 - Micrótomo. Leika modelo 2.065. Alemanha.

4 - Wester Vision Software. USA. to em algumas áreas e espaço intercelular aumentado em sete $(70 \%)$ córneas no grupo controle e em oito $(80 \%)$ no grupo criopreservado. Em seis $(60 \%)$ córneas do grupo controle e sete $(70 \%)$ do criopreservado, a substância própria apresentou aberturas entre as fibras colágenas. Apesar de as alterações diferirem numericamente entre os grupos, a ocorrência deveu-se ao processamento histológico e não pela criopreservação, já que os resultados obtidos são semelhantes nos dois grupos (Figura 2).

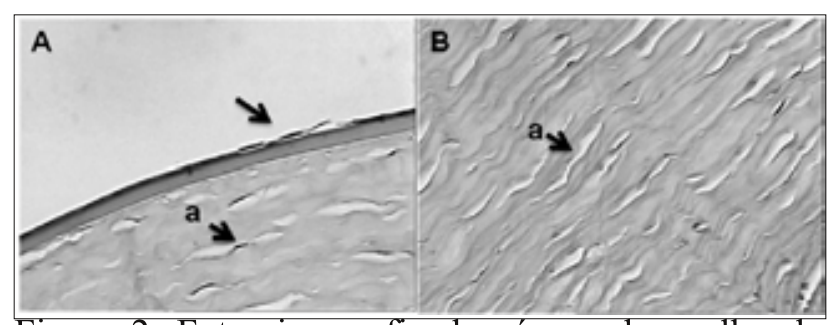

Figura 2. Fotomicrografia da córnea de coelho do grupo controle (A) e criopreservado com etilenoglicol (B). Notar que parte do epitélio posterior apresenta-se solto (A) e aberturas entre as fibras da substância própria (A e B, a - setas), $\mathrm{HE}$ 40x.

Córneas de coelhos foram preservadas em solução sintética de Parker 199, com e sem dextrano $10 \%$, e avaliadas após sete e 14 dias a $4^{\circ} \mathrm{C}$. Com o dextrano ocorreu limitação da hidratação. Notou-se boa conservação da estrutura celular decorridos sete dias e destruição do núcleo aos 14 dias de preservação (WEEKERS \& MICHIELS, 1976). Com o método utilizado neste o trabalho, os núcleos celulares mantiveram-se aparentemente inalterados, com deslocamento mínimo do epitélio posterior.

Córneas de cães e gatos preservadas em Optisol GS a $4^{\circ} \mathrm{C}$ revelaram aberturas dispersadas no epitélio posterior de dimensões aproximadas de uma única célula. As células endoteliais dos animais variaram de 18 a $21 \mu \mathrm{m}$ de largura, sendo geralmente de $15 \mu \mathrm{m}$ (ARNDT et al., 2001). Neste estudo, verificou-se que as células do epitélio posterior do grupo controle apresentavam de 3,03 a $4,41 \mu \mathrm{m}$ de largura e as do grupo criopreservado, de 1,68 a $4,01 \mu \mathrm{m}$, evidenciando que não houve alterações morfométricas significativas. A modificação do epitélio posterior também foi verificada por BOURNE et al. (2001), na preservação de córneas humanas com meio de Chen e Optisol-GS a $4^{\circ} \mathrm{C}$.

Olhos de suínos foram utilizados por ALVIM et al. (2003) para injeção de dextrano 40 a $10 \%$ na câmara anterior e embebidos na mesma solução durante 72 horas. Os autores verificaram que as córne- 
as em solução a $10 \%$ preservaram sua transparência. Com o método de criopreservação em etilenoglicol, utilizado neste trabalho, não foi notada alteração na sua transparência.

Com diferentes concentrações de dimetilssulfóxido, para criopreservação de córneas de cães, O'NEILL et al. (1967) observou que, de 2 a $6 \%$, ocorreu aumento de densidade celular do epitélio posterior, a $8 \%$ grandes áreas da substância própria foi destruída e a $14 \%$ houve destruição do epitélio posterior. Neste trabalho, não foram constatadas lesões do epitélio posterior nem alterações que pudessem ser consideradas como destruição da córnea, nas córneas do grupo controle e criopreser- vadas avaliadas em microscopia de luz.

Para analise das imagens e das mensurações obtidas em microscópio de luz foi utilizado o teste de Kolmogorov e anormalidades na distribuição das mensurações foram observadas. Em seguida, os dados foram submetidos ao teste de comparação de variáveis não paramétricos Wilcoxon. Foi constatado que nenhuma das variáveis pode ser considerada estatisticamente diferente entre o grupo controle e grupo criopreservado. Verificou-se que não houve modificações morfométricas das córneas de coelhos criopreservadas a $-196^{\circ} \mathrm{C}$ em solução de etilenoglicol (Figuras 3, 4, 5 e 6).

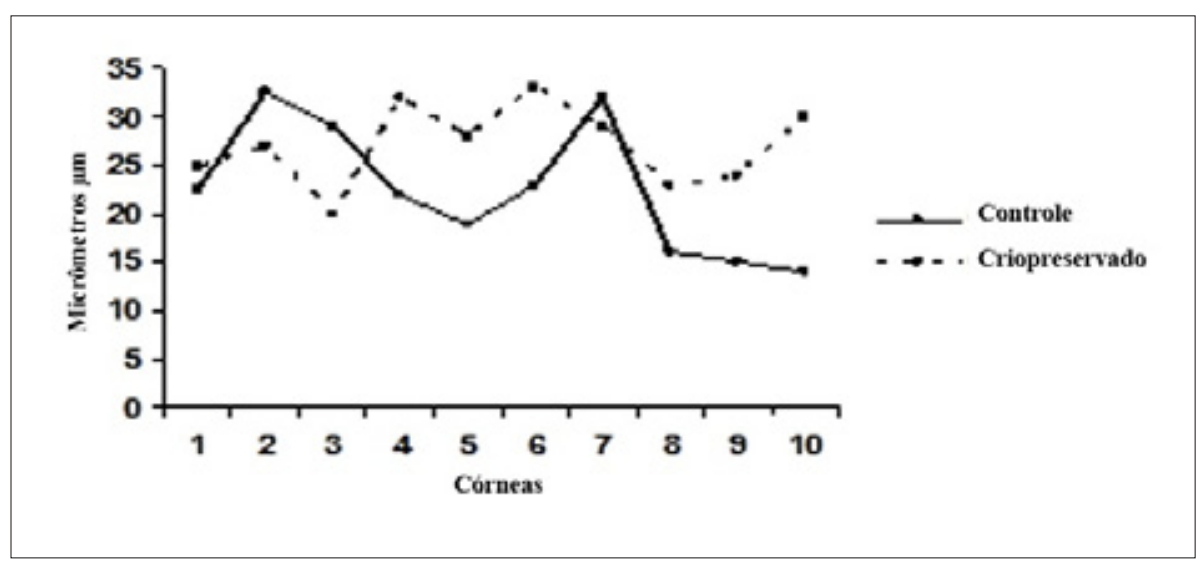

Figura 3. Médias das medidas em micrômetros $(\mu \mathrm{m})$ da espessura do epitélio anterior das córneas de coelhos do grupo controle e do grupo criopreservado.

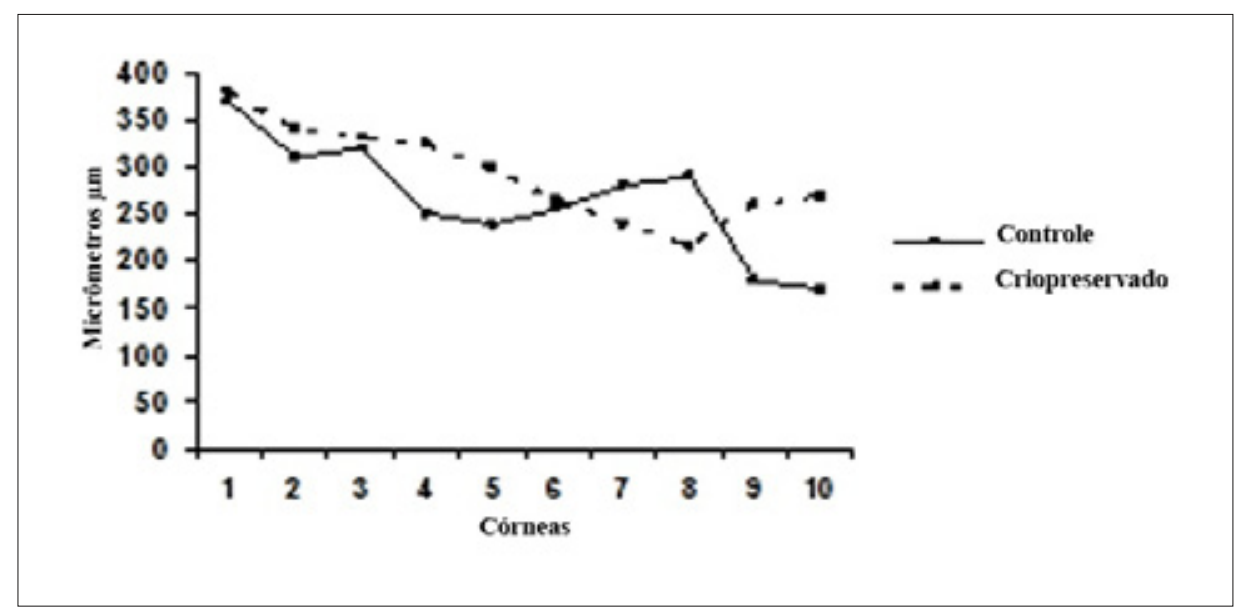

Figura 4. Médias das medidas em micrômetros $(\mu \mathrm{m})$ da espessura da substância própria das córneas de coelhos do grupo controle e do grupo criopreservado. 


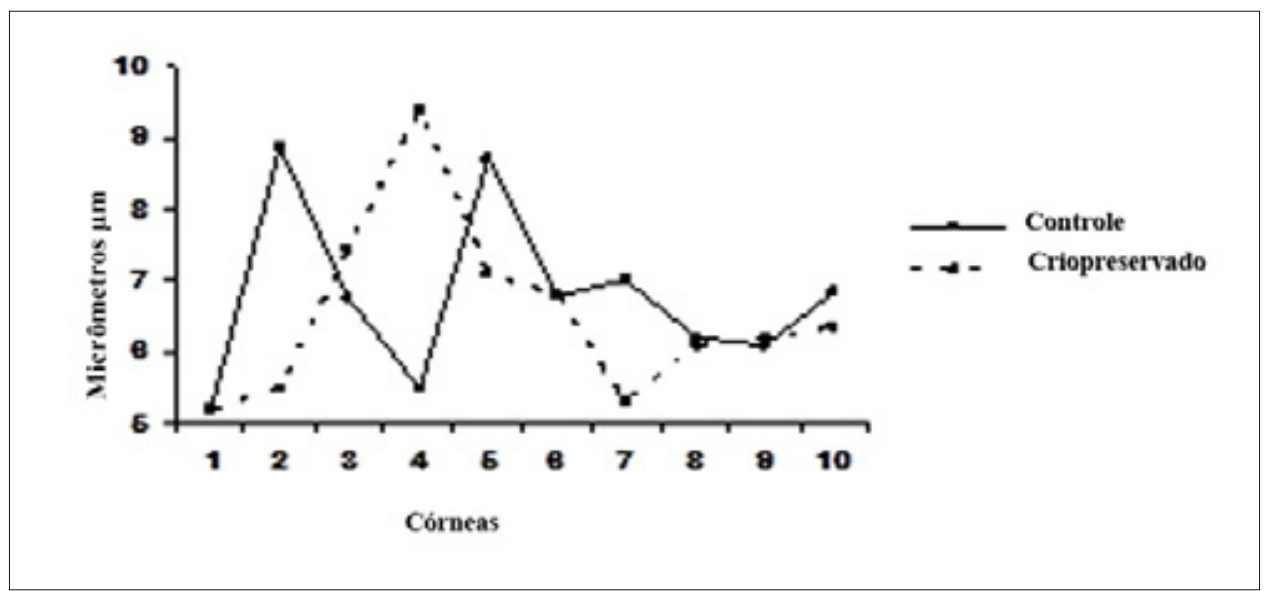

Figura 5. Médias das medidas em micrômetros $(\mu \mathrm{m})$ da espessura da membrana limitante posterior das córneas de coelhos do grupo controle e do grupo criopreservado.

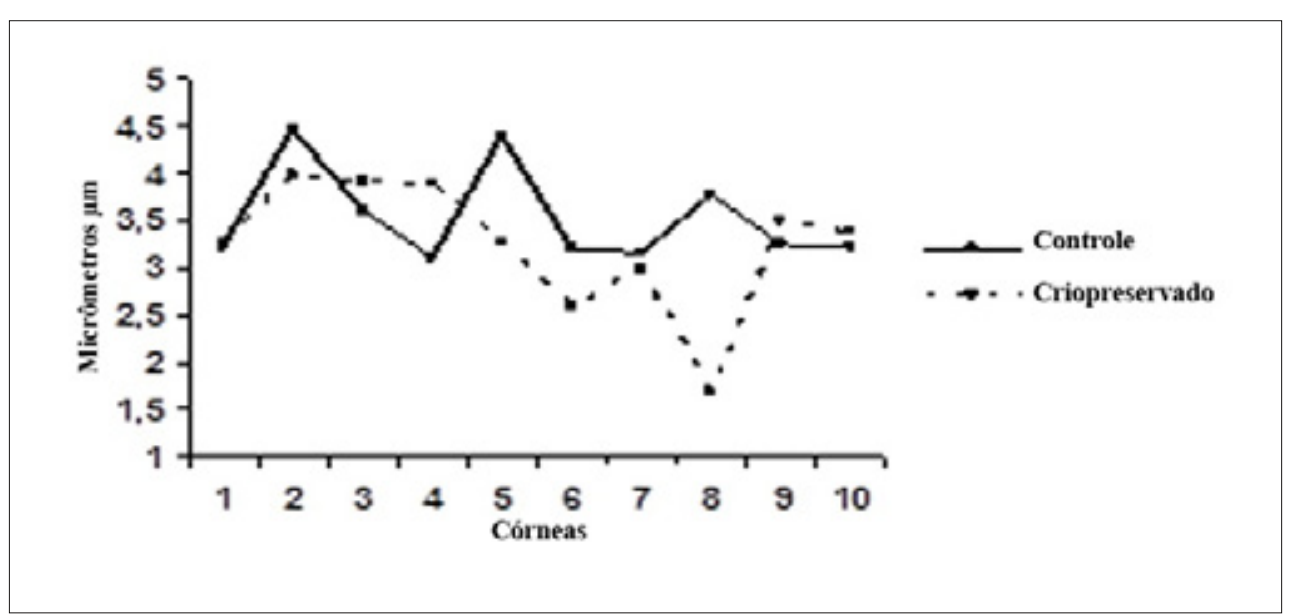

Figura 6. Médias das medidas em micrometros $(\mu \mathrm{m})$ da espessura do epitélio posterior das córneas de coelhos do grupo controle e do grupo criopreservado.

\section{CONCLUSÕES}

A criopreservação de córneas de coelhos com etilenoglicol em nitrogênio líquido durante 60 dias não ocasiona alterações na transparência e nos aspectos estruturais da córnea. A espessura das camadas da córnea não diferiu expressivamente entre o grupo controle e o tratado, o epitélio anterior variou de 15 a $33 \mu \mathrm{m}$ e de 20 a $34 \mu \mathrm{m}$; a substância própria de 375 a $200 \mu \mathrm{m}$ e de 378 a $240 \mu \mathrm{m}$, a membrana limitante de 5,25 a $8,95 \mu \mathrm{m}$ e de 5,22 a $9,31 \mu \mathrm{m}$ e, o epitélio posterior de 3,15 a 4,51 e de 1,85 a $4,00 \mu \mathrm{m}$, respectivamente.

\section{REFERÊNCIAS}

ALMEIDA, A.A. Compêndio de oftalmologia. Rio de Janeiro: Guanabara Koogan, 1974. p.4.

ALVARENGA， M.A.; LANDIN-ALVARENGA，F.C.;
MOREIRA, R.M. CESARINO, M.M. Acrossomal ultrastructure of stallion spermatozoa cryopreserved with ethylene glycol using two packaging systems. Equine Veterinary Journal, v.32, n.6, p.541-545, 2000.

ALVIM, H.S.; DINIZ, C.M.; TZELIKIS, P.F.M.; GONÇALVES, R.M; MAIA, J.A.C. Técnica para preparação e conservação de olhos de porco: para cirurgia experimental. Arquivo Brasileiro de Oftalmologia, n.66, p.627630, 2003.

ANDRADE, A.L.; LAUS, J.L. Enfermidades da córnea de pequenos animais. Clínica Veterinária, v.3, n.12, 1998, p. 34-39.

ARNDT, C.; REESE, S.; KOSTLIN, R. Preservation of canine and feline corneoscleral tissue in Optisol GS. Veterinary Ophthalmology, v.4, n.3, p.175-182, 2001.

BARROS, P.S.; GARCIA, J.A.; LAUS, J.L.; FERREIRA, A.L.; SALLES GOMES, T.L. The use of xenologous amniotic membrane to repair canine corneal perforation created by penetrating keratectomy. Veterinary Ophthalmology, v.1, n.2-3, p.119-123, 1998. 
BERNIS, W.O. Ceratoplastia lamelar experimental em cães. Arquivo Brasileiro de Medicina Veterinária e Zootecnia, v.32, n.3, p.305-323, 1980.

BOURNE, W.M.; NELSON, L.R.; MAGUJIRE, L.J.; BARATZ, K.H.; HODGE, D.O. Comparison of chen medium and Optisol-GS for human corneal preservation at $4^{\circ}$ C. Cornea, v.7, n.20, p.683-686, 2001.

CANALS, M.; COSTA-VILA, J.; POTAU, J.M.; MERINDANO, M.D.; RUANO, D. Morphological study of cryopreserved human corneal endothelium. Cells Tissues Organs, v.164, p. 37-45, 1999.

EURIDES, D.; DALECK, C.R.; SILVA, M.; SILVA, L.A.F.; GONÇALVES, G.F.G.; PRIETO, L.A.; BOREZZI, C. Utilização da cápsula esplênica de bovino na ceratoplastia lamelar em coelhos. Arquivos de Ciências Veterinárias e Zoologia da UNIPAR, v.9, n.2, p.117121, 2006.

GONÇALVES, G.F.; PIPPI, N.L.; RAISER, A.G.; OLIVEIRA. S.T.; GRAÇA, D.L.; MAZZANTI, A.; STEDILE, R. Ceratoplastia lamelar em cão com conservação em solução supersaturada de açúcar ou glicerina - aspectos macroscópicos. Arquivo de Ciências Veterinárias e Zoológicas da UNIPAR, v.6, n.1, p.31-33, 2003.

HALBERSTADT, M.; BOHNKE, M.; ATHMANN, S.; HAGENAH, M. Cryopreservation of human donor corneas with dextran. Investigative Ophthalmology \& Visual Science, University of Hannover, v. 44, n. 12, p. 5110-5115, 2003.

KUHNS, E.L. Conjuntival patch graft for treatment of corneal lesions in dogs. Modern Veterinary Practice, v.60, n.1, p.301-307, 1979.

MORAES, C.N.; NEVES, J.P.; GONÇALVES, P.B.D.; OLIVEIRA, J.F.C;. SCHWEITZER, C. Criopreservação de sêmen ovino em pellets com etileno glicol. Ciência Rural, v.28, n.2, p.287-292, 1998.

MORALES, A.; LAUS, J.L.; SOUZA, M.S.B.; SANTOS, J.M.; FIQUEIREDO, F.; VALERI, V. Comparação entre enxertos livres e pediculados de conjuntiva no repa- ro de ceratectomias superficiais. Estudo experimental em cão (Canis familiaris - Linnaeus, 1758). Brazilian Journal of Veterinary Research and Animal Science, v.33, n.1, p.28-31, 1996.

O'NEILL, P.; MUELLER, F.O.; TREVOR-ROPER, P.D. On the preservation of cornea at $-196^{\circ} \mathrm{C}$ for full-thickness homografts in man and dog. British Journal of Ophthalmology, v.51, n.1, p.13-30, 1967.

PARSHALL, JR. C.J. Lamellar corneal-scleral transposition. Journal of American Animal Hospital Association, v.9, n.3, p.270-277, 1973.

PONTES, K.C.S.; BORGES, A.P.B.; DUARTE, T.S. MORATO, G.L.; ZAVAN, V. ELEOTÉRIO, R.B.; CARLO, E.C. Membrana amniótica canina utilizada como bandagem em úlcera superficial de córnea de coelhos aspectos clínicos. Arquivo Brasileiro de Medicina Veterinária e Zootecnia, v.60, n.5, p.1069-1074, 2008.

ROUTLEDGE, C.; ARMITAGE, W.J. Cryopresevation of cornea: a low cooling rate improves functional survival of endothelium after freezing and thawing. Cryobiology, v.46, n.3, p.277-283, 2003.

SLATTER, D. Fundamentals of veterinary ophthalmology. 3.ed. Philadelphia: Saunders, 2005, p.283.

SOARES, M.P.; ROSSI, C.A.R.; MEZZALIRA, A.; CECIM, M. Etileno glicol na criopreservação de sêmen canino. Ciência Rural, v.32, n.4, p.649-655, 2002.

TRIOLA, F.M. Introdução à estatística. 9.ed. Rio de janeiro: LTC, 2005. 682p.

WEEKERS, J.F., MICHIELS, H. Pachymetry in the study of preservation of the cornea. Archive Ophtalmology, v.36, n.6-7, p.509-522, 1976.

WHITLEY, R.D. Canine cornea. In: GELATT, K.N. Veterinary ophthalmology. 2.ed. Philadelphia: Lea \& Febinger, p.307-356, 1991.

WILLIANS, D. Techniques for treatment of corneal ulcers. Veterinary Practice, v.25, n.17, p.1-6, 1991.

Protocolado em: 12 set. 2010. Aceito em: 03 fev. 2011. 